\title{
Exploring overcrowding trends in an inner city emergence department in the UK before and during COVID-19 epidemic
}

\author{
J. Panovska-Griffiths ${ }^{1,2,3^{*}}$, J. Ross ${ }^{4}$, S. Elkhodair ${ }^{4}$, C. Baxter-Derrington ${ }^{4}$, C. Laing ${ }^{4}$ and R. Raine ${ }^{1}$
}

\begin{abstract}
Background: The COVID-19 pandemic and the associated lockdowns have caused significant disruptions across society, including changes in the number of emergency department (ED) visits. This study aims to investigate the impact of three pre-COVID-19 interventions and of the COVID-19 UK-epidemic and the first UK national lockdown on overcrowding within University College London Hospital Emergency Department (UCLH ED). The three interventions: target the influx of patients at ED (A), reduce the pressure on in-patients' beds (B) and improve ED processes to improve the flow of patents out from ED (C).

Methods: We collected overcrowding metrics (daily attendances, the proportion of people leaving within $4 \mathrm{~h}$ of arrival (four-hours target) and the reduction in overall waiting time) during 01/04/2017-31/05/2020. We then performed three different analyses, considering three different timeframes. The first analysis used data 01/04/201731/12-2019 to calculate changes over a period of 6 months before and after the start of interventions A-C. The second and third analyses focused on evaluating the impact of the COVID-19 epidemic, comparing the first 10 months in 2020 and 2019, and of the first national lockdown (23/03/2020-31/05/2020).
\end{abstract}

Results: Pre-COVID-19 all interventions led to small reductions in waiting time $(17 \%, p<0.001$ for A and C; an 9\%, $p=0.322$ for B) but also to a small decrease in the number of patients leaving within $4 \mathrm{~h}$ of arrival $(6.6,7.4,6.2 \%$ respectively $A-C, p<0.001)$.

In presence of the COVID-19 pandemic, attendance and waiting time were reduced (40\% and 8\%; $p<0.001)$, and the number of people leaving within $4 \mathrm{~h}$ of arrival was increased $(6 \%, \mathrm{p}<0.001)$. During the first lockdown, there was $65 \%$ reduction in attendance, $22 \%$ reduction in waiting time and $8 \%$ increase in number of people leaving within $4 \mathrm{~h}$ of arrival $(p<0.001)$. Crucially, when the lockdown was lifted, there was an increase $(6.5 \%, p<0.001)$ in the percentage of people leaving within $4 \mathrm{~h}$, together with a larger $(12.5 \%, p<0.001)$ decrease in waiting time. This occurred despite the increase of $49.6 \%(p<0.001)$ in attendance after lockdown ended.

\footnotetext{
* Correspondence: j.panovska-griffiths@ucl.ac.uk

'Department of Applied Health Research, UCL, London, UK

${ }^{2}$ Institute for Global Health, University College London, London, UK

Full list of author information is available at the end of the article
}

(c) The Author(s). 2021 Open Access This article is licensed under a Creative Commons Attribution 4.0 International License, which permits use, sharing, adaptation, distribution and reproduction in any medium or format, as long as you give appropriate credit to the original author(s) and the source, provide a link to the Creative Commons licence, and indicate if changes were made. The images or other third party material in this article are included in the article's Creative Commons licence, unless indicated otherwise in a credit line to the material. If material is not included in the article's Creative Commons licence and your intended use is not permitted by statutory regulation or exceeds the permitted use, you will need to obtain permission directly from the copyright holder. To view a copy of this licence, visit http://creativecommons.org/licenses/by/4.0/. The Creative Commons Public Domain Dedication waiver (http://creativecommons.org/publicdomain/zero/1.0/) applies to the data made available in this article, unless otherwise stated in a credit line to the data. 


\begin{abstract}
(Continued from previous page)
Conclusions: The mixed results pre-COVID-19 (significant improvements in waiting time with some interventions but not improvement in the four-hours target), may be due to indirect impacts of these interventions, where increasing pressure on one part of the ED system affected other parts. This underlines the need for multifaceted interventions and a system-wide approach to improve the pathway of flow through the ED system is necessary. During 2020 and in presence of the COVID-19 epidemic, a shift in public behaviour with anxiety over attending hospitals and higher use of virtual consultations, led to notable drop in UCLH ED attendance and consequential curbing of overcrowding.

Importantly, once the lockdown was lifted, although there was an increase in arrivals at UCLH ED, overcrowding metrics were reduced. Thus, the combination of shifted public behaviour and the restructuring changes during COVID-19 epidemic, maybe be able to curb future ED overcrowding, but longer timeframe analysis is required to confirm this.
\end{abstract}

Keywords: Emergency department, Healthcare quality improvement, Health services research, Statistics

\section{Introduction}

The spread of COVID-19 during 2020 has put pressure and induced a number of changes to the National Health Service (NHS) in the UK. To prevent overwhelming the health services, including Emergence Departments (EDs) and to suppress the increasing number of COVID-19 cases in the UK earlier this year, the UK Government imposed strict social distancing measures ("lockdown") from March 23, 2020. As the number of cases started to decline following the lockdown and over the following months, a phased relaxing of the lockdown measures started with primary schools opening on June 01, 2020 and wider relaxing of imposed measures from July 4, 2020. After remaining low during July and August, the number of COVID-19 cases and associated deaths, started to increase again in late August and throughout September 2020. After trialling a Tier system for more localised strict control measures, which was insufficient to curb the large recent resurgence in cases and COVID-19 associated deaths, a second national lockdown was imposed across the UK from November 5, 2020.

EDs provide immediate assessment and care to patients, who may be critically ill. During the first wave of COVID-19, the level of visit to EDs declined sharply; $48 \%$ reduction was reported nationally in April 2020 compared to April 2019 [1]. While awaiting roll-out of an effective vaccine, maintaining social distancing, in conjunction with effective testing, tracing and isolation of positive cases, are the main interventions for virus suppression. Maintaining social distancing is difficult to achieve in overcrowded EDs.

ED treatment in the pre COVID-19 era was often hindered by overcrowding. Contributing factors include seasonal increases in demand, onset of an epidemic or pandemic [2, 3], shortage of available inpatient beds, staff shortage $[4,5]$ and inefficient patient flow through the system $[6,7]$. Previous studies have shown that overcrowding in ED is associated with increased mortality, increased length of stay, reduced quality of care, poor patient experience and increased number of serious incidents [8-11]. However interventions have had varying levels of success [12], and despite ongoing efforts, there is understanding on how to improve ED patient flow [11].

The Royal College of Emergency Medicine suggests that interventions focusing on changes in the input, throughput and output parts of the ED system may be one way of relieving overcrowding [13-15]. Input interventions involve targeting aspects responsible for managing the number of patients attending the ED e.g. relocation of primary care services within emergency care services [16]. However the evidence for this is weak, limited and outdated [17]. Throughput interventions comprise processes within the ED and can include aspects such as staffing, co-ordination with inpatient teams, local protocols and the physical layout of the department. For example training nurses to order an $\mathrm{X}$ rays at triage [18] is a throughput intervention. Finally, output interventions focus on improving the exit of patients from the emergency department, through either admission, discharge or transfer to another service. For example, boarding patients, i.e. sending them to an inpatient ward while waiting for a bed is an output intervention $[19,20]$. However, the evidence base of the effectiveness of these interventions is small, limited and heterogeneous [21, 22].

To improve emergency care provision and reduce prolonged inpatient length of stay, the UK Department of Health and Social Care in 2004 produced a white paper [23] that set a standard target for acute hospitals as part of the National Health Service (NHS) that at least 95\% of patients attending EDs must be seen, treated, admitted or discharged in under $4 \mathrm{~h}$. This still represents the UK's key indicator of an ED performance [24].

Modelling can aid assessment of the impact of different interventions. To date a number of studies have used modelling to quantify the impact of ED system changes 
on ED overcrowding as outlined in recent reviews for the UK system [25] or the USA system [26]. Different modelling approaches such as statistical (regression) modelling, mathematical (i.e. queueing-theory based) modelling and discrete event simulations can be used for this purpose and have different advantages and disadvantages. Generally, statistical modelling is used to evaluate impact of implemented interventions, queueing theory can evaluate flow of people through the ED system and hence explore impact of potential new interventions, while the discrete event simulators allow tracking of individual patents through the system and hence identify potential "clogs" within the system. In existing studies, specific type of models are constructed for the posed question, but often the details of the modelling framework have not always been transparent and difficult to replicate.

In this paper we examine overcrowding in the ED within the University College London Hospitals NHS Foundation Trust, UCLH. Our study is using data from this ED over a long period before the COVID-19 epidemic (April 01, 2017- December 31, 2019) as well as during the first 10 months of the COVID-19 epidemic in 2020. We compare the impact on overcrowding of three trialled interventions at different times pre-COVID-19 to the impact of the presence of the epidemic and the imposed first national lockdown to suppress it and protect the NHS. The three interventions targeted the influx of patients at ED (interventions A), reduced the pressure on in-patients' beds (interventions B) or improved internal ED processes to increase outflow of patents from ED (interventions C) (details in Methods).

\section{Methods}

\section{Setting}

The study was conducted in the Emergency Department of the University College London Hospital (UCLH ED) over the study period April 01, 2017 - October 14, 2020. All patients aged 16 and above attending UCLH ED over this period were included. The study protocol was performed in accordance with the relevant guidelines.

\section{Interventions}

Since April 2017, three groups of interventions targeting different aspects of the UCLH ED have been implemented in timeline shown in Fig. 1. The interventions and their evidence base are summarised in Table 1.

Interventions $\mathrm{A}$ are input interventions that target the pathways of walk-in patients by implementing a triage system where walk-in patients are signposted and diverted directly to other services, including redirecting to community care and directly referred to medical/surgical assessment units. These interventions began in February 2018.

Interventions B aim to reduce the pressure upon available in-patients' beds. They constitute three streams: one throughput stream (B1) that focuses on expansion of the emergency department by adding more mobile beds, and two output streams (B2 and B3) that introduce the same day emergency clinic and a focus on medical emergency assessment unit (EAU). Stream B2 focuses on an expansion of the ambulatory emergency care unit to assess ambulant patients being considered for emergency admission. Stream B3 encompasses opening of an EAU used by the acute medical team as a place to clerk and admit ED patients, in order to free up beds in ED and streamline the medical admission process. It is co-located with the ambulatory emergency care unit, allowing patients to be transferred between them as appropriate. These interventions were established in October 2017.

Finally, interventions $C$ represent throughput interventions that aim to improve ED processes and hence increase flow of patents out from ED. They comprise three streams: optimisation of the workforce by for example having senior or speciality doctors with ED in-reach or having co-located GPs within ED, having same-day emergency clinics and introduction of a digitisation of health records. This revolves around the use of the

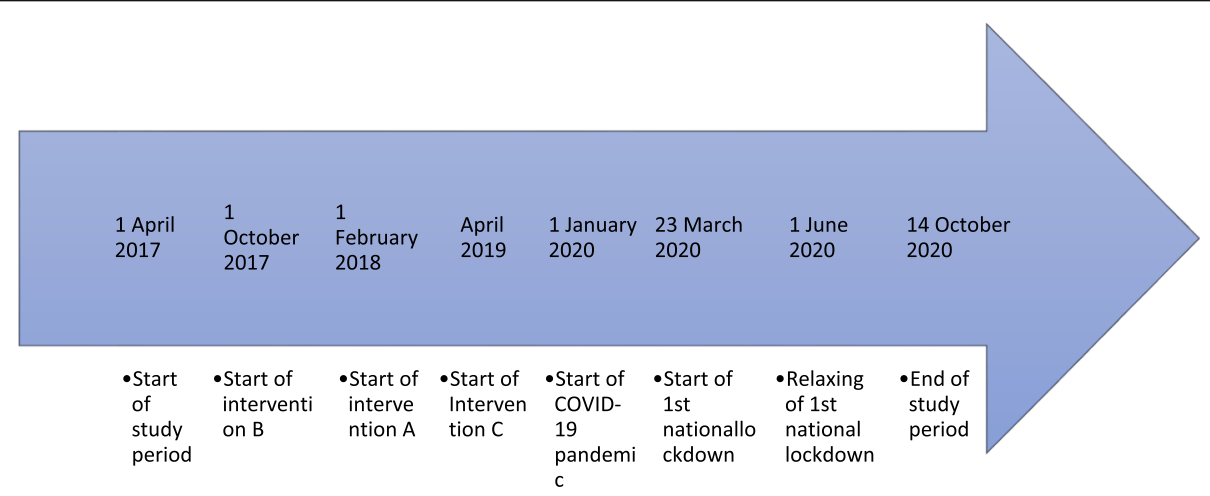

Fig. 1 Timeline of different interventions within the study period 
Table 1 Description and evidence base for different interventions A-C implemented at UCLH ED over the study period with timeline given in Fig 1

\begin{tabular}{|c|c|c|c|}
\hline Intervention target & Intervention name (start date) & $\begin{array}{l}\text { Type of } \\
\text { intervention }\end{array}$ & Summary on extend/strength of intervention \\
\hline $\begin{array}{l}\text { Targeting the influx } \\
\text { of patients }\end{array}$ & $\begin{array}{l}\text { Interventions A: } \\
\text { New triage setting with co-located GP and } \\
\text { presence of senior doctor at UCLH ED } \\
\text { (February 2018) }\end{array}$ & Input stream & $\begin{array}{l}\text { There is some evidence that changes to triage such as } \\
\text { co-locating GPs within triage, having a senior doctor at } \\
\text { triage or having rapid assessment pods within triage, can } \\
\text { be effective in redirecting the flux of incoming patients } \\
\text { and lead to reduced ED waiting time }[16,17,25,27-31] \text {. }\end{array}$ \\
\hline $\begin{array}{l}\text { Reducing pressure upon } \\
\text { available patients' bed }\end{array}$ & $\begin{array}{l}\text { Interventions B } \\
\text { (October 2017) } \\
\text { Stream B1: Expansion of emergency floor } \\
\text { Stream B2:: Same day emergency clinic } \\
\text { Stream B3: Medical EAU }\end{array}$ & $\begin{array}{l}\text { Throughput } \\
\text { stream } \\
\text { Output stream } \\
\text { Output stream }\end{array}$ & $\begin{array}{l}\text { There is some evidence that increasing bed numbers } \\
\text { within ED can reduce ED waiting time [32-34]. } \\
\text { There is some evidence that having the option to redirect } \\
\text { patients arriving at triage to primary care, via same day } \\
\text { emergency clinic may reduce overall ED waiting time } \\
{[11,25] \text {. }} \\
\text { There is some evidence that presence of acute medical } \\
\text { units within EDs can reduce ED waiting times [35-37]. }\end{array}$ \\
\hline $\begin{array}{l}\text { Improving internal } \\
\text { processes to increase } \\
\text { outflow }\end{array}$ & $\begin{array}{l}\text { Interventions C: } \\
\text { (April 2019) } \\
\text { Facilitation the workup of patients to include } \\
\text { three streams: optimisation of workforce, } \\
\text { clinical pathway and full digitisation of ED }\end{array}$ & $\begin{array}{l}\text { Throughput } \\
\text { streams }\end{array}$ & $\begin{array}{l}\text { There is some evidence that interventions including } \\
\text { improving specialty in-reach to ED or GPs working within } \\
\text { the ED }[11,16,31] \text { or boarding patients [38] or digitization } \\
\text { of the records within the Electronic Health Records (EHRs) } \\
\text { database [39] can reduce ED overcrowding. }\end{array}$ \\
\hline
\end{tabular}

Electronic Health Records (EHRs) database as a fully electronic health record system that has been introduced across the Trust including the UCLH ED. This allows single sign on for clinicians and a consistent health record for patients replacing paper notes and prescription charts. Interventions C began in April 2019.

\section{Design}

Interrupted time series analysis (ITS) and regression analysis.

\section{Data}

Routine hourly data on the number of patients arriving at UCLH ED over the study period of 42 months were collated. This period includes 6 months (April 01, 2017September 30, 2017) before any interventions were implemented and a period of 8 months after the last intervention was implemented (April, 012019-December 31, 2020). It also includes the first 10 months of the UK COVID-19 epidemic in 2020 (January 01, 2020-October 14, 2020). People arriving at UCLH ED were grouped into people walking into UCLH ED or arriving by ambulance.

\section{Statistical analysis}

We constructed time series of the daily arrivals of patients at UCLH ED over the period April 01, 2017October 14, 2020. Using the data, we truncated the observation period into two periods: April 01, 2017December 31, 2020 and January 01,2020-October 14, 2020; the former period representing pre-COVID-19 era and the latter COVID-19 period in the UK in 2020 for which we have data. The pre-COVID-19 era included periods of before and after intervention for each of the three sets of interventions A-C. The COVID-19 period included the period in 2020 during the first national lockdown (March 23, 2020-May 31, 2020) ('lockdown') and the period before and after the first COVID-19 epidemic wave. The timeline of our work is schematically represented in Fig. 1. The dataset gave us sufficient power for statistical analysis.

Using these different time periods of the available data we undertook three separate but linked analysis.

The first analysis focused on the impact of trialled interventions in the pre-COVID-19 era on overcrowding at UCLH ED. For this analysis we used the timeseries between April, 01, 2017 and December 31, 2020 (inclusive). Over this period we defined the start of each set of interventions A, B and C; respectively February 01, 2018, October 01, 2017 and April 01, 2019. We then calculated the changes in the overcrowding metrics over a period of 6 months before and after the start of each intervention.

The second and third analysis focused on evaluating the impact of the COVID-19 epidemic and the first national lockdown on overcrowding in UCLH ED.

The second analysis compared the number of attendances, \% of people leaving within $4 \mathrm{~h}$ of arrival and the average daily waiting time over the first 10 months of 2019 and 2020 (January 01-October 14) i.e. in absence and presence of the COVID-19 epidemic. Additionally we also compared the first national lockdown period (March 23, 2020-May 31, 2020) in both years. By looking at all three overcrowding metrics, this analysis informed whether overcrowding changes were a result of lowered attendances at this ED during 2020 or a consequence of COVID-19-induced changes here. We note that to accommodate COVID-19 safe environment, a number of 
changes were made in this ED during the first epidemic wave e.g. rapid assessment and triage were stopped and adaptations were made to facilitate more rapid flow of patients through the ED (e.g. segregated pathways, streaming patients, some patients went in escalated treatments such as non-invasive ventilation before leaving the ED etc).

For the third analysis, we split the data from 2020 into three time periods of 71 days defined as period before the first national lockdown (January 12, 2020-March 22, 2020) ('before lockdown'), period during the first national lockdown (March 23, 2020-May 31, 2020) ('lockdown') and period after the first national lockdown (June 01, 2020-August 11, 2020)('after lockdown'). For each of these periods we compared the number of attendances, $\%$ of people leaving within $4 \mathrm{~h}$ of arrival and the average daily waiting time. This analysis informed whether lockdown significantly affected overcrowding in this ED.

For each analysis, we used mixed effects negative binomial regression models to quantify the changes in the three overcrowding metrics, projecting the incidence rate ratios (IRRs) for all people attending UCLH ED as well as split between those arriving by ambulance and walking in, the \% of people leaving within $4 \mathrm{~h}$ and the average time spend in UCLH ED (henceforth waiting time). To account for differences associated with the intervention period, we fitted a random intercept model with a single indicator variable for "during-intervention/ lockdown" for each intervention and the lockdown. To estimated standard errors we used bootstrapping with 500 replications and also reported the $95 \%$ confidence intervals (95\% CI) and $p$-values. All the statistical analysis was undertaken in Stata v16.

(a) Attendances at UCLH ED over the study period

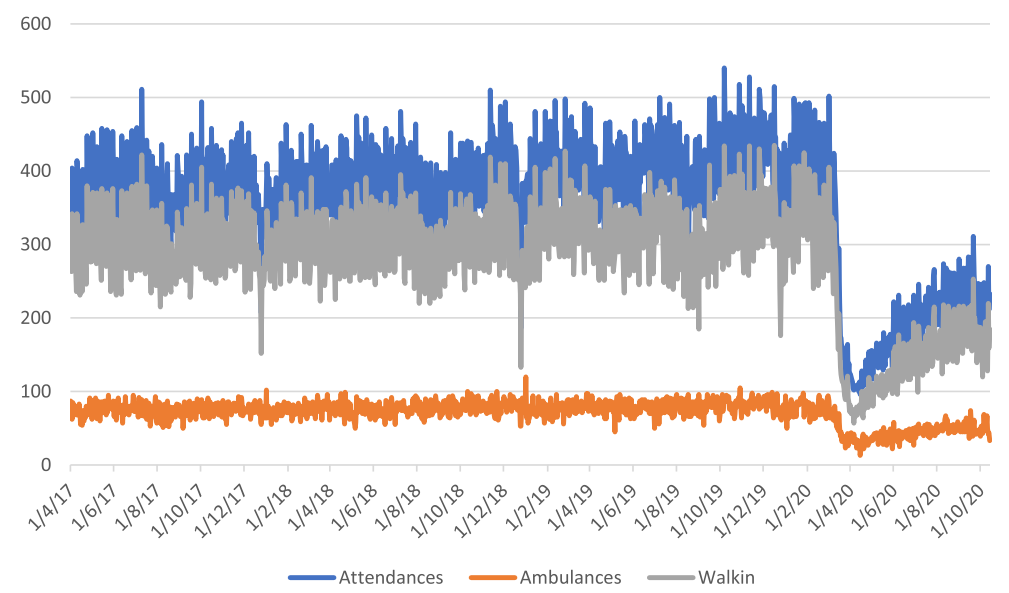

(b) Percentage of people leaving UCLH ED within 4 hours of arrival

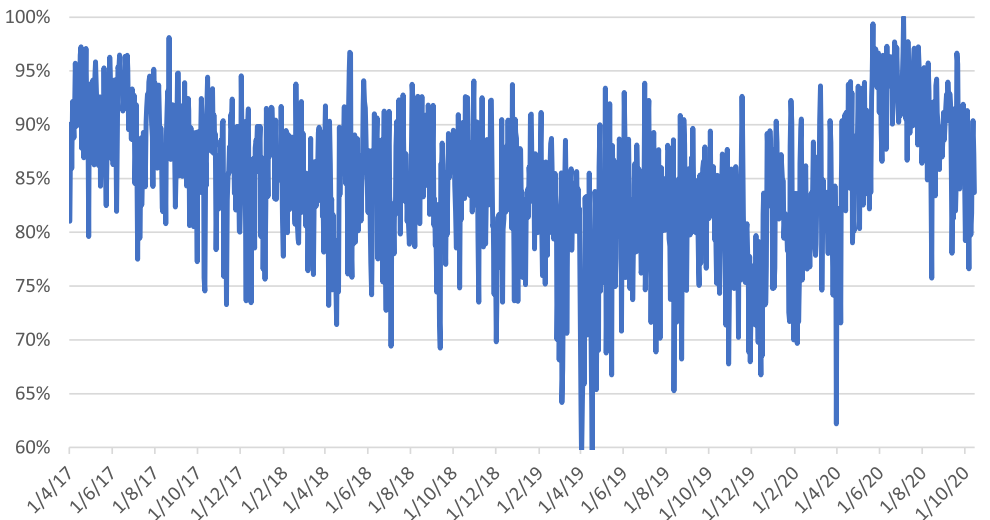

Fig. 2 (a)-(b): a) Timeseries of number of people attending UCLH ED over the study period stratified by people arriving by ambulance and walking-in. There is a large drop in attendances that coincides with the imposing of the first national COVID-19 lockdown. While this drop is evident for both walk-in and ambulance patients, it is larger in walk-in patients. b) Timeseries of the number of people leaving UCLH ED within $4 \mathrm{~h}$ of arrival 


\section{Results}

\section{Descriptive statistics over the study period}

Figure 2(a) and (b) contain, respectively, the timeseries of the attendances at UCLH ED and the percentage of people that left within $4 \mathrm{~h}$ of arrival in the period between April 1, 2017 and October 14, 2020. We observe that there was almost constant level of attendance at this ED in the period before March 2020 with a notable drop in attendances that coincides with the onset of the first national lockdown (23/03/2020).

Over the entire study period, a total of 458,456 patients attended UCLH ED of whom 92,362 (20.1\%) arrived by ambulance and 366,094 (79.8\%) patients walked-in. Daily, on average 355 patients attended UCLH ED, with 72 patients arriving by ambulance and an average of 283 patients walkingin. The average time spend at UCLH ED was $3.5 \mathrm{~h}(95 \% \mathrm{CI}=$ $[3.3,3.6])$, with times spend by patients coming by ambulance spending on average $4.6 \mathrm{~h}(95 \% \mathrm{CI}=[4.3,4.9])$, while patients walking-in spending, on average, $3.2 \mathrm{~h}(95 \% \mathrm{CI}=[3.0,3.4])$ at UCLH ED. Finally, the average proportion of people leaving UCLH ED within $4 \mathrm{~h}$ of arrival was $84.8 \%(95 \% \mathrm{CI}=[84.4$, $85.2 \%]$ ).

\section{Impact of trialed interventions in the pre-COVID-19 era}

The results of the first analysis showing the impact of the overcrowding interventions $\mathrm{A}-\mathrm{C}$ on the overcrowding metrics are contained in Table 2.

The number of people attending UCLH ED increased slightly, albeit statistically significant, in the period after implementation of interventions A, B and C (Table 2, rows 3-5). The increase in numbers of patients

Table 2 Outcomes from the ITS analysis projecting the impact of interventions $A, B$ and $C$ on the overcrowding indicators. The study period is truncated into periods before and after the start of each intervention $A, B$ and $C$; respectively starting on February 01, 2018, October 01, 2017 and April 01, 2019. We calculate the changes over a period of 6 months before and after the start of each intervention

\begin{tabular}{lcc}
\hline \multicolumn{3}{l}{ Changes in number of people attending UCLH ED } \\
\hline Intervention & IRR $(\mathbf{9 5 \%}$ Cl) & $\boldsymbol{p}$-value \\
\hline interventions A & $1.058(1.041,1.075)$ & $<0.001$ \\
Interventions B & $1.053(1.034,1.071)$ & $<0.001$ \\
Interventions C & $1.074(1.057,1.091)$ & $<0.001$ \\
Changes in \% of people leaving within 4h of arrival & \\
Interventions A & $0.935(0.927,0.943)$ & $<0.001$ \\
Interventions B & $0.926(0.919,0.934)$ & $<0.001$ \\
Interventions C & $0.938(0.929,0.947)$ & $<0.001$ \\
Changes in average waiting time & \\
Interventions A & $0.834(0.734,0.949)$ & 0.005 \\
Interventions B & $0.913(0.763,1.092)$ & 0.322 \\
Interventions C & $0.832(0.773,0.896)$ & $<0.001$ \\
\hline
\end{tabular}

attending UCLH ED after implementation of interventions A (row 3 of Table 2) was 5.8\%, for interventions B was $5.3 \%$ (row 4 of Table 2) and for interventions $C$ was $7.4 \%$ (row 5 of Table 2).

There was a small but statistically significant decrease in number of people leaving within $4 \mathrm{~h}$ of arrival (rows 7-9 of Table 2). For interventions A this reduction was $6.6 \%(p<$ 0.001 ), from 88.5 to $82 \%$. For interventions $B$ this reduction was $7.4 \%(\mathrm{p}<0.001)$ from 90.4 to $83 \%$ of people leaving within $4 \mathrm{~h}$ of arrival (Table 2). Finally, for interventions $\mathrm{C}$ this reduction was $6.2 \%(\mathrm{p}<0.001)$, from 86.2 to $80 \%$ of people leaving within $4 \mathrm{~h}$ of arrival.

The average waiting time spend by patients at UCLH ED was reduced by 38 min (17\%) after implementation of interventions $\mathrm{A}(p=0.005)$ and $\mathrm{C}(\mathrm{p}<0.001)$ (rows 11 and 13 of Table 2 respectively). With implementation of intervention $\mathrm{B}$, the average waiting time was reduced by $20 \mathrm{~min}(9 \%)$ but this was not statistically significant ( $p=$ 0.322 in row 12 of Table 2).

\section{Impact of COVID-19 on overcrowding}

The results of the second and third analysis showing the impact of the epidemic and the lockdown on overcrowding metrics in this ED are shown in Table 3.

Our second analysis suggested that in the presence of the COVID-19 epidemic, overcrowding in UCLH ED was reduced. During 2020, there was a notable drop in the number of attendances at UCLH ED that coincides with the onset of the first national lockdown (Fig. 2(a) and Table 3). While drop in attendances was evident in both people walking in UCLH ED and people arriving with ambulances, the decrease in those walking in was larger (Fig. 2(a) and Table 3).

Specifically, during the period January 01, 2020October 14, 2020, a total of 69,491 patients attended UCLH ED of which 14,837 (21.4\%) arrived by ambulance and 54,654 (78.63\%) patients walked-in. This was a $39.3 \%$ reduction in visits to this ED in comparison to the same period in 2019. In addition, comparing these periods in 2019 and 2020, we determined that there was $8 \%$ reduction in waiting time and $6 \%$ increase in number of people leaving within $4 \mathrm{~h}$ of arrival (Table 3 ).

Considering only the period of the first national lockdown (March 23-June 01) in 2019 and 2020, these changes were even more dramatic: $65.3 \%$ reduction in attendance and $21.9 \%$ reduction in waiting time and $8.3 \%$ increase in number of people leaving within $4 \mathrm{~h}$ of arrival (Table 3).

For the third analysis, considering 2020 only, our results suggest that the lockdown significantly affected the three overcrowding metrics. In comparison to the period before the lockdown, the lockdown led to $65.4 \%$ reduction in attendance $(52.7 \%$ in those arriving by ambulance and $69.2 \%$ in those walking in), $12.4 \%$ reduction in 
Table 3 Outcomes from the ITS analysis projecting the impact of the first national lockdown ('lockdown') to suppress COVID-19 during the spring of 2020 on the overcrowding metrics and considering all attendances and those arriving by ambulance or walking in. The study period (over the period January 12, 2020August 11,2020$)$ is split into three time periods of 71 days defined as before the first national lockdown (January 12, 2020March 22, 2020) ('before'), during the first national lockdown (March 23, 2020-May 31, 2020) ('lockdown') and after the first national lockdown (June 01, 2020-August 11, 2020)('after')

\begin{tabular}{|c|c|c|}
\hline \multicolumn{3}{|c|}{ Impact of COVID-19 lockdown on all people attending UCLH ED } \\
\hline Intervention & IRR (95\% Cl) & $p$-value \\
\hline Lockdown VS before lockdown & $0.346(0.324,0.369)$ & $<0.001$ \\
\hline After lockdown VS lockdown & $1.496(1.417,1.576)$ & $<0.001$ \\
\hline \multicolumn{3}{|c|}{ Impact of COVID-19 lockdown people arriving by ambulance to UCLH ED } \\
\hline Lockdown VS before lockdown & $0.473(0.443,0.505)$ & $<0.001$ \\
\hline After lockdown VS lockdown & $1.285(1.211,1.362)$ & $<0.001$ \\
\hline \multicolumn{3}{|c|}{ Impact of COVID-19 lockdown people walking-in the UCLH ED } \\
\hline Lockdown VS before lockdown & $0.308(0.287,0.331)$ & $<0.001$ \\
\hline After lockdown VS lockdown & $1.596(1.506,1.692)$ & $<0.001$ \\
\hline \multicolumn{3}{|c|}{ Impact of COVID-19 lockdown in \% of people leaving within $4 \mathrm{~h}$ of arrival } \\
\hline Lockdown VS before lockdown & $1.059(1.034,1.085)$ & $<0.001$ \\
\hline After lockdown VS lockdown & $1.075(1.053,1.098)$ & $<0.001$ \\
\hline \multicolumn{3}{|c|}{ Impact of COVID-19 lockdown on average waiting time } \\
\hline Lockdown VS before lockdown & $0.876(0.839,0.915)$ & $<0.001$ \\
\hline After lockdown VS lockdown & $0.868(0.837,0.899)$ & $<0.001$ \\
\hline
\end{tabular}

waiting time and $5.9 \%$ increase in number of people leaving within $4 \mathrm{~h}$ of arrival; all statistically significant (Table 3).

Once the strict social distancing measures were lifted, there was an $49.6 \%$ increase in attendances to UCLH ED (28.5\% in those arriving by ambulance and $59.6 \%$ in those walking in) (Table 3). But interestingly, compared to during lockdown, in the period afterwards, the waiting time was reduced by $13.2 \%$, while the number of people leaving within $4 \mathrm{~h}$ of arrival was increased by $7.5 \%$; all changes statistically significant (Table 3).

\section{Discussion}

All three sets of interventions A-C trialled in the preCOVID-19 era led to small reductions of waiting time over the 2 years before the epidemic. These reductions were significant in the case of interventions A (that targeted the influx of patients at ED) and interventions $C$ (that improved internal ED processes to increase outflow of patents from ED) but were not in the case of interventions $B$ (that aimed to reduce the pressure on inpatients' beds). In addition, all three trialled interventions were also associated with a small, but significant decrease in the number of patients leaving the ED within $4 \mathrm{~h}$ of arrival. Therefore with the trialled interventions pre-COVID-19 no improvement was evident in the fourhours target.

During 2020 and in presence of the COVID-19 pandemic, there was a drop in attendance at this ED and as a result, waiting times were reduced and the percentage of people leaving within $4 \mathrm{~h}$ or arrival increased. This result is unsurprising: the drop in attendances at UCLH ED compared to the same periods in 2019 reflects the national data $[1,40]$. Crucially, however when the lockdown was lifted following the first wave of COVID-19, there was both an increase $(6.5 \%)$ in the percentage of people leaving within $4 \mathrm{~h}$, together with a larger $(12.5 \%)$ decrease in waiting time. This occurred despite the increase of $49.6 \%$ in ED attendance after lockdown ended.

The mixed results found pre-COVID-19 (significant improvements in waiting time with some interventions but fewer people leaving UCLH ED within $4 \mathrm{~h}$ of arrival), may be due to indirect impacts. For example, clogging up one part of the ED system e.g. triage will have a knock on effect and increased pressure on the outflow of patients. This is simply due to the fact that large influx will produce a bottle neck effect within the system. In a situation where there is limited capacity in terms or inpatients' beds or a complex system of discharging from hospitals, this will lead to lower outflow through the system i.e. elevated overcrowding. Therefore, in line with existing literature [41, 42], there is a need for the entire pathway of flow through the ED system to be examined and a system-wide improvement to be implemented. This needs to include separate parts (a) deciding the priority measure of overcrowding (b) identifying the stream of blockages within different parts that affect it and (c) taking an informed approach with engagement of staff to design and implement a modular strategy.

Our findings reflect those in the literature. For example, a systematic review [38] of the effectiveness of interventions on reducing ED crowding by older patients between 1990 and 2017 showed that none of the implemented interventions reduced all overcrowding measures. Our findings of the need for multifaceted interventions and a system-wide approach is also supported by the literature [11]. For example, results in [38] suggest that rapid assessment and streaming of care for older adults arriving at the ED lead to a statistically significant decrease of ED length of stay. This is analogous to how implementation of interventions A led to statistically significant reduction of the time spend in ED in our study. Similarly, existing work showed that the presence of an ED-based consultant geriatrician was associated with significant time reduction between patient admission and geriatric review compared to an in- 
reaching geriatrician [41]. This has parallels with our findings that implementation of interventions $\mathrm{C}$ leads to reduction to the time spend in $\mathrm{ED}$.

Our results also reflect the existing literature on the impact of COVID-19 on ED overcrowding [1, 43, 44] and add to it. For example, our findings of the drop in visit to EDs during the first lockdown, reflect the nationally reported decline of $48 \%$ reduction in attendances in April 2020 compared to April 2019 [1, 40]. The drop in attendance during the first stages of the pandemic spread, compared to these being stable in the preCOVID-19 period, are also in agreement with the findings from a study in the inner city ED of the University Hospital of Parma, Italy [43] and across 24 EDs from five American states [44]. The literature across these studies agrees that the COVID-19 pandemic lead to reduced attendance of EDs and as a consequence overcrowding was curbed.

A shift in public behaviour during the first wave of the pandemic can explain these results. For example, during the first lockdown period in the UK, when the public was instructed to 'stay at home, save lives and protect the NHS', anxiety over presenting in hospitals and higher use of NHS 111 and other advice lines occurred [1]. Nationally, this led to a decline in number of arrivals within EDs with minor injuries $[1,40]$. This allowed ambulance services to more effectively respond to people with more severe needs. In addition, primary care services made a substantive shift to virtual primary care consultations [40], which gave immediate access to patients with less severe injuries. Hence, the reduction in overcrowding in 2020 compared to 2019, would have been due to changes in the ways in which people with less severe needs gained immediate access to services virtually and hence attended EDs less frequently, leading to more appropriate use of the ED services.

After the first COVID-19 wave, an increase was evident in attendances in this ED and notably from patients walking in (Fig. 2(a)). Despite this, waiting time at UCLH ED was reduced while the number of people leaving UCLH ED within $4 \mathrm{~h}$ of arrival was increased. We note two things. Firstly, the increase in UCLH ED attendance after the first lockdown has not yet reached baseline pre-COVID-19 level (Fig. 2(a)). Secondly, a large restructuring of EDs, including UCLH ED has occurred as part of the COVID-19 epidemic response. Hence, the combination of shifted public behaviour of more appropriate use of EDs and the system-wide restructuring changes during COVID-19 epidemic would have increased flow of patients in this ED and hence curb ED overcrowding during 2020. It is important to assess whether this remains the case in future, and while our study is the first to study thus, we are aware that a longer timeframe analysis is necessary to confirm this.
We note that our study has some limitations. Firstly, when comparing the first 10 months of 2019 and the first 10 months of 2020 we have taken a simplistic approach that doesn't account for the fact that these period are inhomogeneous. Specifically, during the first 3 months of 2019 interventions $C$ were not applied yet, while in the first 10 months of 2020, and in response to the COVID-19 epidemic a number of changes and responsive interventions were employed in this ED. Furthermore, when comparing the "lockdown" timeframe (March 23, June 01) in 2019 and 2020 we note that there is a theoretical difference between the two periods, since for example interventions $C$ were applied from April 01 in 2019. Secondly, we have not untangled in our analysis the key patients cohorts (e.g. those with respiratory symptoms, or cardiovascular symptoms, or trauma patents) most likely to be attending this ED during the COVID-19 epidemic. While this is an interesting follow on study, it is beyond the scope of the current work. Thirdly, we note that interventions A and B overlap for some of the pre/post-intervention period, but we didn't feel they are confounding factors to each other's impact. This is because, although taking part at the same time over the overlapping periods, the relevant interventions were independent of each other. An alternative, would have been to use 3 months as the evaluation period across all interventions but since interventions take time to start, we felt that 6 months was in this study a more realistic evaluation period.

The choice of statistical modelling in this study also has some limitations. Our method, interrupted time series, can effectively compare changes in outcomes for successive groups of patients before and after ED interventions/lockdown started, and is therefore fit for the purpose of this study. But whilst such regression modelling is useful in drawing conclusion for the duration of the study where fitted curves mimic the data, the presence of turning points in the non-linear fits makes them unreliable for prediction beyond the period for which data are available. An alternative would be to develop and utilise queuing theory models e.g. [45], that model the flow of patients through a system.

Another possible future direction in research would be use of automated learning systems, rooted in higher-order statistical methods e.g. machine learning, that will allow real-time assessment of patients arriving at ED. A recent review [46] has collated the existing literature on the application of AI methods in emergency medicine, concluding that although some attempts have been made in the field, this an emerging field that will benefit from application of tailor-made machine learning algorithms for reallife assessment of, for example, arrival and triage assessment. Future work could combine the use of Electronic Health Records and robust machine learning algorithms. 


\section{Conclusions}

In summary, our study found that trialled interventions pre-COVID-19 lead to mixed results: significant improvements in waiting time with interventions that targeted the influx of patients at ED (A) or improved internal ED processes to increase outflow of patents from ED $(\mathrm{C})$, but fewer people leaving UCLH ED within $4 \mathrm{~h}$ of arrival. This is likely because of the indirect impacts of these interventions, where increasing pressure on one part of the ED system affected other parts. This underlines a need for multifaceted interventions and a system-wide approach to improve the entire pathway of flow through the ED system.

During 2020 and in presence of the COVID-19 epidemic, a shift in public behaviour with anxiety over presenting in hospitals and higher use of NHS 111 or virtual primary consultations, UCLH ED attendance dropped notably, and as a consequence waiting time was reduced while the percentage of people leaving the ED within $4 \mathrm{~h}$ was increased.

Importantly, once the lockdown was lifted, there was an increase in arrivals at UCLH ED, but not yet reaching the pre-COVID-19 attendance level. As a result, even with this increase the overcrowding metrics were reduced. Therefore, it may be possible that shift in public behaviour to more appropriately use EDs combined with the systemwide restructuring changes during COVID-19 epidemic would be able to curb overcrowding in future, but longer timeframe analysis is required to attest this.

\section{Acknowledgements}

Not applicable.

\section{Authors' contributions}

JPG had the idea for the study, undertook the statistical analysis and drafted the manuscript. Data was supplied by CBD. Collation of existing interventions was done by JPG, JR and CE with input from CL. The manuscript was written by JPG, with contributions from JR, RR, SE CBD and $\mathrm{CL}$ to manuscript's revision and refinement. All authors read and approved the final manuscript.

\section{Funding}

This research was in part funded by the National Institute for Health Research (NIHR) Collaboration for Leadership in Applied Health Research and Care North Thames at Bart's Health NHS Trust (NIHR CLAHRC North Thames). This funder had no role in study design, data collection, data analysis, data interpretation, or writing of the report. The views expressed in this article are those of the authors and not necessarily those of the NHS, the NIHR, or the Department of Health and Social Care. The funder had no role in this study.

\section{Availability of data and materials}

The datasets used and analysed during this study and the numerical codes used to generate the outcomes of this paper are available from the corresponding author on reasonable request.

\section{Declarations}

\section{Ethics approval and consent to participate}

This study is considered a retrospective service evaluation and as such is exempt and ethics approval and informed consent for current study is waived by the UCL Research Ethics Committee.
Consent for publication

Not applicable.

\section{Competing interests}

We declare no competing interests.

\section{Author details}

${ }^{1}$ Department of Applied Health Research, UCL, London, UK. ${ }^{2}$ Institute for Global Health, University College London, London, UK. ${ }^{3}$ The Wolfson Centre for Mathematical Biology and The Queen's College, University of Oxford, Oxford, UK. ${ }^{4}$ Emergency Department, University College London NHS Foundation Trust, London, UK.

Received: 10 December 2020 Accepted: 23 March 2021

Published online: 06 April 2021

\section{References}

1. McConkey R, Wyatt S. Exploring the fall in A\&E visits during the pandemic. The Health Foundation report. https://www.health.org.uk/news-andcomment/charts-and-infographics/exploring-the-fall-in-a-e-visits-during-thepandemic. Assessed 10/11/2020

2. Schull MJ, Mamdani MM, Fang J. Influenza and emergency department utilization by elders. Acad Emerg Med Off J Soc Acad Emerg Med. 2005; 12(4):338-44. https://doi.org/10.1197/j.aem.2004.11.020.

3. Schanzer DL, Schwartz B. Impact of Seasonal and Pandemic Influenza on Emergency Department Visits, 2003-2010, Ontario, Canada. Acad Emerg Med. 2013;20(4):388-97. Published online 2013. https://doi.org/10.1111/a cem.12111.

4. Cooke MW, Wilson S, Halsall J, et al. Total time in English accident and emergency departments is related to bed occupancy. Emerg Med J EMJ. 2004;21(5):575-6. https://doi.org/10.1136/emj.2004.015081.

5. Sun BC, Mohanty SA, Weiss R, Tadeo R, Hasbrouck M, Koenig W, et al. Effects of hospital closures and hospital characteristics on emergency department ambulance diversion, Los Angeles County, 1998 to 2004. Ann Emerg Med. 2006;47(4):309-16. https://doi.org/10.1016/j.annemergmed.2 005.12.003.

6. Bair AE, Song WT, Chen Y-C, Morris BA. The impact of inpatient boarding on ED efficiency: a discrete-event simulation study. J Med Syst. 2010;34(5):91929. https://doi.org/10.1007/s10916-009-9307-4.

7. Kolker A. Process modeling of emergency department patient flow: effect of patient length of stay on ED diversion. J Med Syst. 2008;32(5):389-401. https://doi.org/10.1007/s10916-008-9144-x.

8. Boyle A, Higginson I. This emergency department crisis was predictable and partly preventable. BMJ. 2018;360:k64.

9. Hoot NR, Aronsky D. Systematic Review of Emergency Department Crowding: Causes, Effects, and Solutions. Ann Emerg Med. 2008;52(2):126136.e1 Available from: http://www.sciencedirect.com/science/article/pii/S01 96064408006069.

10. Trzeciak S, Rivers EP. Emergency department overcrowding in the United States: an emerging threat to patient safety and public health. Emerg Med J. 2003;20(5):402-5 Available from: http://www.ncbi.nlm.nih.gov/pubmed/12 954674

11. Yarmohammadian MH, Rezaei F, Haghshenas A, et al. Overcrowding in emergency departments: A review of strategies to decrease future challenges. J Res Med Sci. 2017;22:23. Published online 2017 Feb 16. https:// doi.org/10.4103/1735-1995.200277.

12. Morley C, Unwin M, Peterson GM, Stankovich J, Kinsman L. Emergency department crowding: a systematic review of causes, consequences and solutions. Plos One. 2018;13(8):e0203316. https://doi.org/10.1371/journal. pone.0203316.

13. The Royal College of Emergency Medicine (2015). Tackling Emergency Department Crowding. Available from: https://www.rcem.ac.uk/docs/ College\%20Guidelines/5z23.\%20ED\%20crowding\%20overview\%20and\%2 Otoolkit\%20(Dec\%202015).pdf

14. Emergency Care Intensive Support Team, NHS IMAS. Effective approaches in urgent and emergency care: Papers 1-4 (2011-2013). Available from: https://www.nhsimas.nhs.uk/fileadmin/Files/IST/ECIST_Priorities_within_A cute_Hospitals_2011.pdf. Access date 10/03/2021.

15. The Royal College of Emergency Medicine (2014). Crowding in emergency departments, Revised June 2014. Available from: https://www.rcem.ac.uk/ 
docs/Service\%20Design\%20+\%20Delivery/52b.\%20RCEM\%20Crowding\%2 0Guideline\%20(2015).pdf

16. Cooper A, Davies F, Edwards M, Anderson P, Carson-Stevens A, Cooke MW, et al. The impact of general practitioners working in or alongside emergency departments: A rapid realist review. BMJ Open. 2019;9(4). https://doi.org/10.1136/bmjopen-2018-024501.

17. Cooper A, Carson-Stevens A, Hughes T, Edwards A. Is streaming patients in emergency departments to primary care services effective and safe? BMJ. 2020;368:m462. https://doi.org/10.1136/bmj.m462.

18. Lindley-Jones $\mathrm{M}$, Finlayson $\mathrm{BJ}$. Triage nurse requested $\mathrm{x}$ rays - are they worthwhile? J Accid Emerg Med. 2000;17(2):103-7. https://doi.org/10.1136/ emj.17.2.103.

19. American College of Emergency Physicians. Boarding of admitted and intensive care patients in the emergency department. Ann Emerg Med. 2011;58(1):110

20. Walsh P, Cortez V, Bhakta H. Patients would prefer ward to emergency department boarding while awaiting an inpatient bed. J Emerg Med. 2008; 34(2):221-6. https://doi.org/10.1016/j.jemermed.2007.05.012.

21. Mohiuddin S, Busby J, Savovic J, et al. Patient flow within UK emergency departments: a systematic review of the use of computer simulation modelling methods. BMJ Open. 2017;7(5):e015007. https://doi.org/10.1136/ bmjopen-2016-015007.

22. Cassarino M, Robinson K, Quinn R, Naddy B, O'Regan A, Ryan D, et al. Impact of early assessment and intervention by teams involving health and social care professionals in the emergency department: a systematic review. Plos One. 2019;14(7):e0220709. https://doi.org/10.1371/journal.pone.0220709.

23. UK Department of Health, white paper, https://publications.parliament.uk/ $\mathrm{pa} / \mathrm{cm} 200405 / \mathrm{cmselect} / \mathrm{cmpubacc} / 445 / 445 . \mathrm{pdf}$, Accessed 7 Oct 2019.

24. lacobucci G. NHS is to test scrapping the four hour a\& E target. BMJ. 2019;364: 11148 Available from: http://www.bmj.com/content/364/bmj.11 148.abstract.

25. White BA, Brown DFM, Sinclair J, et al. Supplemented triage and rapid treatment (START) improves performance measures in the emergency department. J Emerg Med. 2012;42(3):332-28. https://doi.org/10.1016/j. jemermed.2010.04.022 PMID: 20554420.

26. Burstrom $L$, Engstro $M-L$, Castren $M$, et al. Improved quality and efficiency after the introduction of physician-led team triage in an emergency department. Upsala J Med Sci. 2016;121(1):38-44. https://doi.org/10.3109/03 009734.2015.1100223 PMID: 26553523.

27. Ming T, Lai A, Lau PM. Can Team Triage Improve Patient Flow in the Emergency Department? A Systematic Review and Meta-Analysis. Adv Emerg Nurs J. 2016;38(3):233-50. https://doi.org/10.1097/TME. 0000000000000113.

28. Rowe BH, Villa-Roel C, Guo X, Bullard MJ, Ospina M, Vandermeer B, et al. The role of triage nurse ordering on mitigating overcrowding in emergency departments: a systematic review. Acad Emerg Med. 2011;18(12):1349-57. https://doi.org/10.1111/j.1553-2712.2011.01081.x.

29. Rowe BH, Guo X, Villa-Roel C, Schull M, Holroyd B, Bullard M, et al. The role of triage liaison physicians on mitigating overcrowding in emergency departments: a systematic review. Acad Emerg Med. 2011;18(2):111-20. https://doi.org/10.1111/j.1553-2712.2010.00984.X.

30. Bullard MJ, Villa-Roel C, Guo X, Holroyd BR, Innes G, Schull MJ, et al. The role of a rapid assessment zone/pod on reducing overcrowding in emergency departments: a systematic review. Emerg Med J. 2012;29(5):372-8. https:// doi.org/10.1136/emj.2010.103598.

31. Abdulwahid MA, Booth A, Kuczawski M, Mason SM. The impact of senior doctor assessment at triage on emergency department performance measures: systematic review and meta-analysis of comparative studies Emerg Med J. 2016;33(7):504-13. https://doi.org/10.1136/emermed-2014-2 04388.

32. Mumma BE, McCue JY, Li CS, et al. Effects of emergency department expansion on emergency department patient flow. Acad Emerg Med. 2014; 21(5):504-9. https://doi.org/10.1111/acem.12366 PMID: 2484250.

33. Thomas Schneider AJ, Luuk Besselink P, Zonderland ME, et al. Allocating Emergency Beds Improves the Emergency Admission Flow. INFORMS J Appl Anal. 2018;48(4):384-94. https://doi.org/10.1287/inte.2018.0951.

34. McNaughton $C$, Self WH, Jones ID, Arbogast PG, Chen N, Dittus RS, et al. Emergency Department Crowding and the Use of Nontraditional Beds. Am J Emerg Med. 2012;30(8):1474-80. https://doi.org/10.1016/j.ajem.2011.12.007.

35. Zager K, Taylor YJ. Discharge to medical home: a new care delivery model to treat non-urgent cases in a rural emergency department. Healthc (Amst). 2019;7(1):7-12. https://doi.org/10.1016/j.hjdsi.2018.08.001.
36. Lauks J, Mramor B, Baumgartl K, et al. Medical team evaluation: effect on emergency department waiting time and length of stay. Plos One. 2016; 11(4). https://doi.org/10.1371/journal.pone.0154372 PMID: 27104911.

37. Scott I, Vaughan L, Bell D. Effectiveness of acute medical units in hospitals: a systematic review. Int J Qual Heal care J Int Soc Qual Heal Care. 2009;21(6): 397-407. https://doi.org/10.1093/intghc/mzp045.

38. Hesselink G, Sir O, Schoon Y. Effectiveness of interventions to alleviate emergency department crowding by older adults: a systematic review. BMC Emerg Med. 2019;19:69.

39. Ben-Assuli O, Leshno M, Shabtai I. Using electronic medical record systems for admission decisions in emergency departments: examining the crowdedness effect. J Med Syst. 2012;36(6):3795-803. https://doi.org/10.1 007/s10916-012-9852-0.

40. COVID-19: Resetting Emergency Department Care, The Royal College of Emergency Medicine report. https://www.rcem.ac.uk/RCEM/Quality_Policy/ Policy/COVID19_Resetting_Emergency_Care/RCEM/Quality-Policy/Policy/ COVID-19_Resetting_Emergency_Care.aspx. Assessed 26/11/2020

41. Hurwitz JE, Lee JA, Lopiano KK, et al. A flexible simulation platform to quantify and manage emergency department crowding. BMC Med Inform Decis Mak. 2014;14:50. Published online 2014 Jun 9. https://doi.org/10.11 86/1472-6947-14-50.

42. Electronic Health System Records at UCLH, https://www.uclh.nhs.uk/a boutus/NewDev/EHRS/Pages/Newtechnology.aspx. Access date 10/03/2021.

43. Comelli I, Scioscioli F, Cervellin G. Impact of the COVID-19 epidemic on census, organization and activity of a large urban Emergency Department. Acta Biomed. 2020;91(2):45-9. https://doi.org/10.23750/abm.v91i2.9565.

44. Jeffery MM, D'Onofrio G, Paek H, Platts-Mills TF, Soares WE 3rd, Hoppe JA, et al. Trends in emergency department visits and hospital admissions in health care systems in 5 states in the first months of the COVID-19 pandemic in the US. JAMA Intern Med. 2020;180(10):1328-33. https://doi. org/10.1001/jamainternmed.2020.3288.

45. Crowe S, Grieco L, Vindrola-Padros C, et al. How can operational research and ethnography help to fix your emergency department? J Roy Soc Med. 2019;112(10):415-9. https://doi.org/10.1177/0141076819856879.

46. Shafaf $\mathrm{N}$, Malek $\mathrm{H}$. Applications of machine learning approaches in emergency medicine; a review article. Arch Acad Emerg Med. 2019;7(1):34.

\section{Publisher's Note}

Springer Nature remains neutral with regard to jurisdictional claims in published maps and institutional affiliations.

Ready to submit your research? Choose BMC and benefit from:

- fast, convenient online submission

- thorough peer review by experienced researchers in your field

- rapid publication on acceptance

- support for research data, including large and complex data types

- gold Open Access which fosters wider collaboration and increased citations

- maximum visibility for your research: over $100 \mathrm{M}$ website views per year

At BMC, research is always in progress.

Learn more biomedcentral.com/submissions 